\title{
Postnatal Changes in Cerebral Oxygen Extraction in the Preterm Infant Are Associated with Intraventricular Hemorrhage and Hemorrhagic Parenchymal Infarction but Not Periventricular Leukomalacia
}

\author{
CHRISTOPHER M. KISSACK, ROSALINE GARR, STEPHEN P. WARDLE, AND \\ A. MICHAEL WEINDLING \\ Neonatal Unit, Liverpool Women's Hospital, Liverpool, L8 7SS, U.K. [C.M.K., R.G., A.M.W.], and \\ Neonatal Unit, Queen's Medical Centre, University Hospital, Nottingham HG7 2UH, U.K. [S.P.W.]
}

\begin{abstract}
Fluctuations in cerebral hemodynamics have been implicated in the pathogenesis of acquired brain damage in babies born prematurely. This study examined the changes in cerebral fractional oxygen extraction (FOE) over the first $3 \mathrm{~d}$ after birth in 25 verylow-birth-weight preterm infants. Twelve infants had no major cerebral injury and 13 had acquired brain injury; cystic periventricular leukomalacia (PVL) was present in 4 and intraventricular hemorrhage (IVH) in 9, of whom 2 also had hemorrhagic parenchymal infarction (HPI). Normal values (median, $5^{\text {th }}-95^{\text {th }}$ centiles) for cerebral FOE in very-low-birth-weight infants with no cerebral injury were $0.38(0.23-0.53)$ on $\mathrm{d} 1,0.31(0.18-0.45)$ on $\mathrm{d} 2$, and $0.28(0.17-0.38)$ on d 3. Infants who developed cystic PVL had no significant change in cerebral FOE during the first $3 \mathrm{~d}$ after birth. By contrast, cerebral FOE fluctuated in infants with IVH over the $3 \mathrm{~d}$ of measurement, decreasing from $\mathrm{d} 1$ to $\mathrm{d} 2(p=0.03)$ and increasing from $\mathrm{d} 2$ to $\mathrm{d} 3(p=0.02)$. The highest cerebral FOE values were
\end{abstract}

ABSTRACT

seen in the two infants with HPI. The different patterns of change in cerebral FOE with HPI and cystic PVL provide additional evidence that the pathogenesis of these two conditions is different. Because high cerebral FOE is likely to be a consequence of low cerebral oxygen delivery, probably because of low cerebral blood flow, our results indicate that fluctuations in cerebral blood flow may occur when there is IVH or HPI. (Pediatr Res 56: 111-116, 2004)
FOE, fractional oxygen extraction
PVL, periventricular leukomalacia
IVH, intraventricular hemorrhage
HPI, hemorrhagic parenchymal infarction
$\mathrm{SvO}_{2}$, venous oxygen saturation
$\mathrm{SaO}_{2}$, arterial oxygen saturation

Cerebral white matter injury is responsible for considerable morbidity in infants born prematurely (1-5). The two principal underlying brain lesions are HPI and cystic PVL (6). Abnormal cerebral hemodynamics and oxygen delivery have been suggested as possible etiological factors for both lesions (7). Increased variability in cerebral blood flow or mean arterial blood pressure have been associated with the development of IVH (8-11). By contrast, cystic PVL has been attributed to cerebral hypoperfusion $(8,12-14)$. Other studies, however, have demonstrated no relationship between the incidence of PVL and hypotension (15-17). There is also emerging evi-

Received February 18, 2003; accepted September 9, 2003.

Correspondence: C.M. Kissack, M.D., Neonatal Unit, Liverpool Women's Hospital, Crown St., Liverpool, L8 7SS, U.K.; e-mail: uknearinfrared@yahoo.co.uk

Supported by the National Health Service Research and Development Executive, the Newborn Appeal, and Action Research.

DOI: 10.1203/01.PDR.0000128984.03461.42 dence to implicate infection and inflammation, and the vulnerability of the oligodendrocyte precursors that inhabit the developing periventricular white matter, in the etiology of PVL (18-24).

Another variable that is related to cerebral perfusion and oxygen delivery is cerebral FOE, which represents the ratio of cerebral oxygen consumption to cerebral oxygen delivery. As oxygen delivery decreases, FOE would be expected to increase so that oxygen consumption remains constant. When oxygen delivery decreases beyond the critical point at which oxygen extraction is maximal and cannot increase further, oxygen consumption will start to decrease. This present study was undertaken to investigate the patterns of change in cerebral FOE over the first $3 \mathrm{~d}$ after birth in preterm, very-low-birthweight neonates, and to relate these changes to acquired cerebral injury. The hypothesis that was tested was that infants with no major cerebral injury would exhibit a different pattern of 
cerebral FOE during the first days after birth than those who developed IVH, HPI, or cystic PVL.

\section{METHODS}

Subjects. Thirty-six infants $<32$ wk of gestation and with birth weights $<1500 \mathrm{~g}$ were studied. These infants were all delivered at the Liverpool Women's Hospital during a 17-mo period, between November 1999 and March 2001 inclusive. All infants received conventional mechanical ventilation. Informed consent was obtained before making near-infrared measurements. The study was approved by the Local Paediatrics Ethics Committee.

Cerebral FOE. Cerebral $\mathrm{SvO}_{2}$ was measured with a partial jugular venous occlusion technique using near-infrared spectroscopy (Hammamatsu NIRO 500, Hamamatsu Photonics UK Ltd., Welwyn Garden City, Hertfordshire, U.K.) and pulse oximetry (Datex-Ohmeda, Helsinki, Finland). The technique has been described and validated against invasive measurements (25). Near-infrared optodes were placed in a frontotemporal arrangement on the head, and the interoptode distance was measured using calipers. All interoptode distances were between 2.5 and $4.0 \mathrm{~cm}$. Data quality criteria were preset: near-infrared measurements of $\mathrm{SvO}_{2}$ were considered acceptable only if there was a preceding steady baseline for both $\mathrm{Hb}$ and oxyhemoglobin $(\mathrm{HbO})$, followed by a rise in both during the partial jugular venous compression, with both returning to the preexisting baseline immediately after the compression.

The $\mathrm{SaO}_{2}$ was measured using the pulse oximeter in beatto-beat mode, taking a reading every $0.5 \mathrm{~s}$, with the probe located on the infant's right hand. The mean $\mathrm{SaO}_{2}$ for the $5 \mathrm{~s}$ immediately preceding the partial jugular venous occlusion was taken as the value for $\mathrm{SaO}_{2}$.

At least five separate partial jugular venous occlusions were performed for each measurement, and the mean values of $\mathrm{SaO}_{2}$ and $\mathrm{Svo}_{2}$ from the five readings were used to calculate cerebral FOE, using the formula:

$$
\mathrm{FOE}=\left(\mathrm{SaO}_{2}-\mathrm{SvO}_{2}\right) / \mathrm{SaO}_{2}
$$

The derivation of this formula is set out in detail elsewhere (26). Measurements of cerebral $\mathrm{SvO}_{2}$ were made within the first $12 \mathrm{~h}$ after birth (d 1), between 24 and $36 \mathrm{~h}$ of age (d 2), and between 48 and $60 \mathrm{~h}$ of age (d 3).

Cranial ultrasound. Examinations were performed on d 1, 3 , and 7 after delivery. Thereafter, scans were performed weekly, until $1 \mathrm{mo}$ of age, and from then on monthly until discharge from the neonatal intensive care unit. Infants had additional cranial ultrasound scans on other days during the course of the study, as considered appropriate by the attending physician.

Statistics. Data were analysed using SPSS Version 10.0.7 (SPSS Inc., Chicago, IL, U.S.A.). Normality of data was ascertained using histogram plots and Shapiro-Wilk test. A normal range for cerebral FOE was defined using $5^{\text {th }}$ and $95^{\text {th }}$ centiles generated from data in those infants who did not have evidence of cerebral injury on cranial ultrasound. Cerebral FOE in infants with cerebral injury was compared with the normal ranges. Further analysis of the data were performed using nonparametric methods, because of analysis of repeated measurements within individuals, and because of the small number of infants in each group. Differences in cerebral FOE across the $3 \mathrm{~d}$ of measurement were examined using Friedman's test. Where significant differences were found, the data were visually examined and, if appropriate, differences between $\mathrm{d} 1$ and 2 and $\mathrm{d} 2$ and 3 were analyzed using the Wilcoxon signed rank test, to determine on which days the significant changes in cerebral FOE occurred.

\section{RESULTS}

Measurements. Thirty-six infants were studied. There were successful measurements of cerebral FOE on all $3 \mathrm{~d}$ in 25 infants. Ten infants had two successful measurements, and one infant had only one successful measurement completed. The reasons for failure of the 12 missing measurements were death before the $\mathrm{d} 3$ of life (1 measurement), equipment failure (2 measurements), and rejection of recorded data for failure to meet preset standards, usually because of movement artifact $(9$ measurements). Only the 25 infants who underwent three complete measurements were included in the analysis. The 11 infants excluded for failure to complete three measurements as laid out in the study protocol were not significantly different with regard to gestation, birth weight, or sex.

Descriptive details for the 25 infants are shown in Table 1.

Changes in cerebral FOE. There was a significant $(p=$ $0.01)$ decrease in mean cerebral FOE from d $1(0.37 \pm 0.10)$ to d $2(0.30 \pm 0.09)$, a decrease of $18.9 \%$ (Table 2, Fig. 1). There was no significant change from $\mathrm{d} 2$ to $\mathrm{d} 3$.

The 25 infants were divided into three groups based on their cranial ultrasound findings: 12 had either no cerebral injury or subependymal hemorrhages alone; 4 had cystic PVL; 9 had IVH confined to the cerebral ventricles, including 2 infants, referred to below as infants $\mathrm{A}$ and $\mathrm{B}$, who had HPI during the first $3 \mathrm{~d}$ after birth. The infants with no cerebral injury or subependymal hemorrhages alone $(n=12)$ were not significantly different from infants with cerebral injury $(n=13)$ with regard to gestation, birth weight, or sex.

Cerebral FOE in infants with no major cerebral injury. Cerebral FOE values in the infants with no major cerebral injury $(n=12)$ demonstrated a pattern of change similar to that seen in the group as a whole (Fig. 2), although with no significant change during the $3 \mathrm{~d}$ of measurement (Table 2). The data from this group were used to generate a normal range based on the $5^{\text {th }}$ and $95^{\text {th }}$ centiles for cerebral FOE on each of the three days of measurement. The $5^{\text {th }}-95^{\text {th }}$ centile ranges were $0.23-0.53$ on $\mathrm{d} 1,0.18-0.45$ on $\mathrm{d} 2$, and $0.17-0.38$ on $\mathrm{d}$ 3 (Fig. 2). Cerebral FOE values in the three groups with cerebral injury were then related to this normal range.

Table 1. Descriptive details for 25 infants with three complete data sets

\begin{tabular}{lc}
\hline & Median (range) \\
\hline Gestation (wk) & $26(23-30)$ \\
Birth weight $(\mathrm{g})$ & $910(452-1378)$ \\
Time of measurement d 1 (h) & $7(3-12)$ \\
Time of measurement d 2 (h) & $28(24-36)$ \\
Time of measurement d 3 (h) & $52(48-60)$ \\
\hline
\end{tabular}


Table 2. Cerebral FOE over d 1-3

\begin{tabular}{|c|c|c|c|c|c|c|}
\hline & Day 1 & Day 2 & Day 3 & $\mathrm{p}^{1}$ & $\mathrm{p}^{2}$ & $\mathrm{p}^{3}$ \\
\hline All infants $(n=25)$ & $0.37( \pm 0.10)$ & $0.30( \pm 0.09)$ & $0.30( \pm 0.09)$ & 0.03 & 0.01 & NS \\
\hline No major injury $(n=12)$ & $0.38(0.35-0.40)$ & $0.31(0.26-0.39)$ & $0.28(0.26-0.34)$ & NS & $\mathrm{N} / \mathrm{A}$ & $\mathrm{N} / \mathrm{A}$ \\
\hline Cystic PVL $(n=4)$ & $0.33(0.25-0.38)$ & $0.29(0.26-0.33)$ & $0.24(0.23-0.27)$ & NS & $\mathrm{N} / \mathrm{A}$ & $\mathrm{N} / \mathrm{A}$ \\
\hline
\end{tabular}

Cerebral FOE for all infants is presented as mean $( \pm \mathrm{SD})$. Data for the three subgroups are presented as median (interquartile range). Statistical analysis of changes within the groups was performed using Friedman's Test, with results shown in column $\mathrm{p}^{1}$. Further analysis of changes between $\mathrm{d} 1$ and 2 (column $\mathrm{p}^{2}$ ) and $\mathrm{d} 2$ and 3 (column $\mathrm{p}^{3}$ ), were performed using Wilcoxon signed rank test. N/A, statistical analysis not appropriate due to nonsignificant Friedman's test.

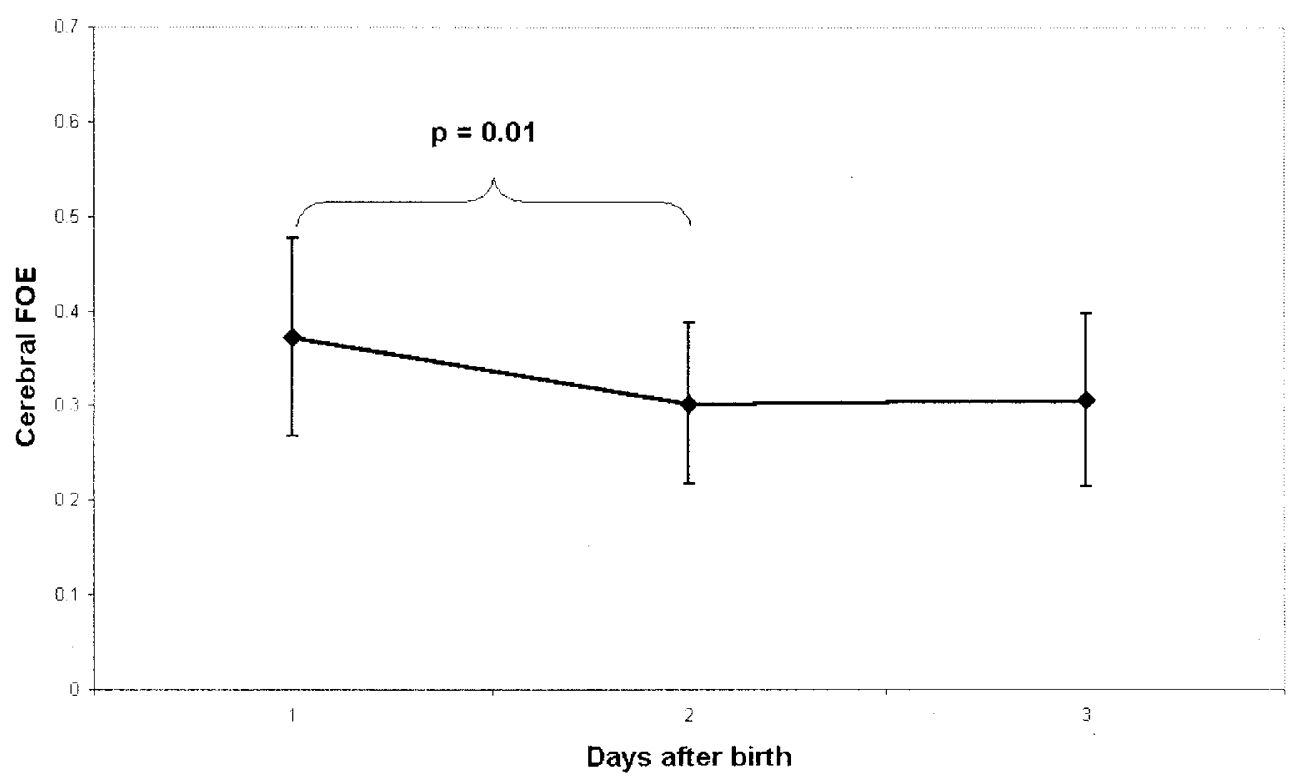

Figure 1. Cerebral FOE during the first $3 \mathrm{~d}$ after birth in all infants. Data are presented as means with error bars representing 1 SD. There was a significant decrease in median cerebral FOE from $\mathrm{d} 1$ to $\mathrm{d} 2$.

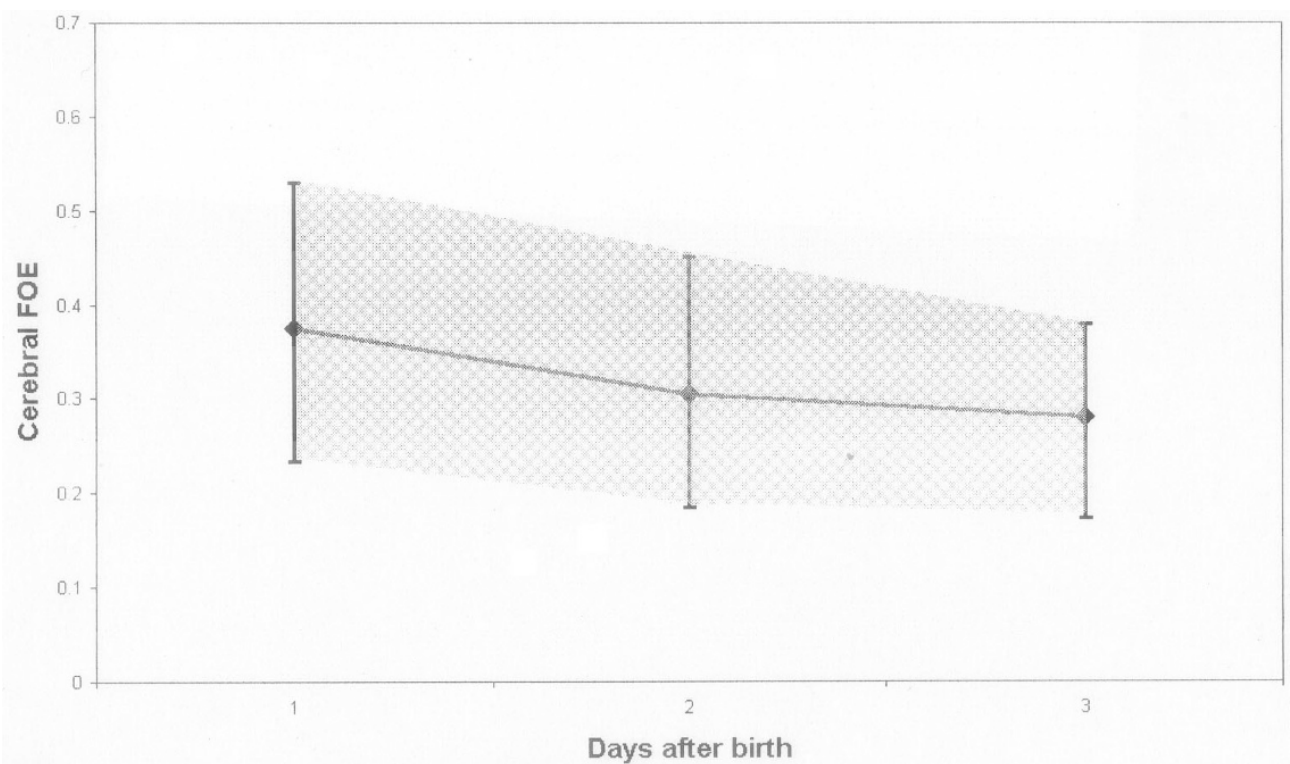

Figure 2. Cerebral FOE during the first $3 \mathrm{~d}$ after birth in 12 infants with no cerebral injury or subependymal hemorrhage only. Data are presented as medians, with error bars representing $5^{\text {th }}$ and $95^{\text {th }}$ percentile limits. The shaded area represents the region between the $5^{\text {th }}$ and $95^{\text {th }}$ percentiles during the first $3 \mathrm{~d}$ after birth. There was no significant change in cerebral FOE during the $3 \mathrm{~d}$.

Cerebral FOE in infants with cystic PVL. Four infants developed cystic PVL. In one, the cysts were first seen on d 1, in the other three cysts were first seen on $\mathrm{d} 19,20$, and 26. There was no significant change in cerebral FOE during the $3 \mathrm{~d}$ of measurement (Table 2).
None of these infants had measurements of cerebral FOE above the $95^{\text {th }}$ centile, although 1 of 12 measurements was below the $5^{\text {th }}$ centile (Fig. 3 ).

Cerebral FOE in infants with IVH and HPI. Nine infants developed IVH, of whom seven had injury confined to the cere- 


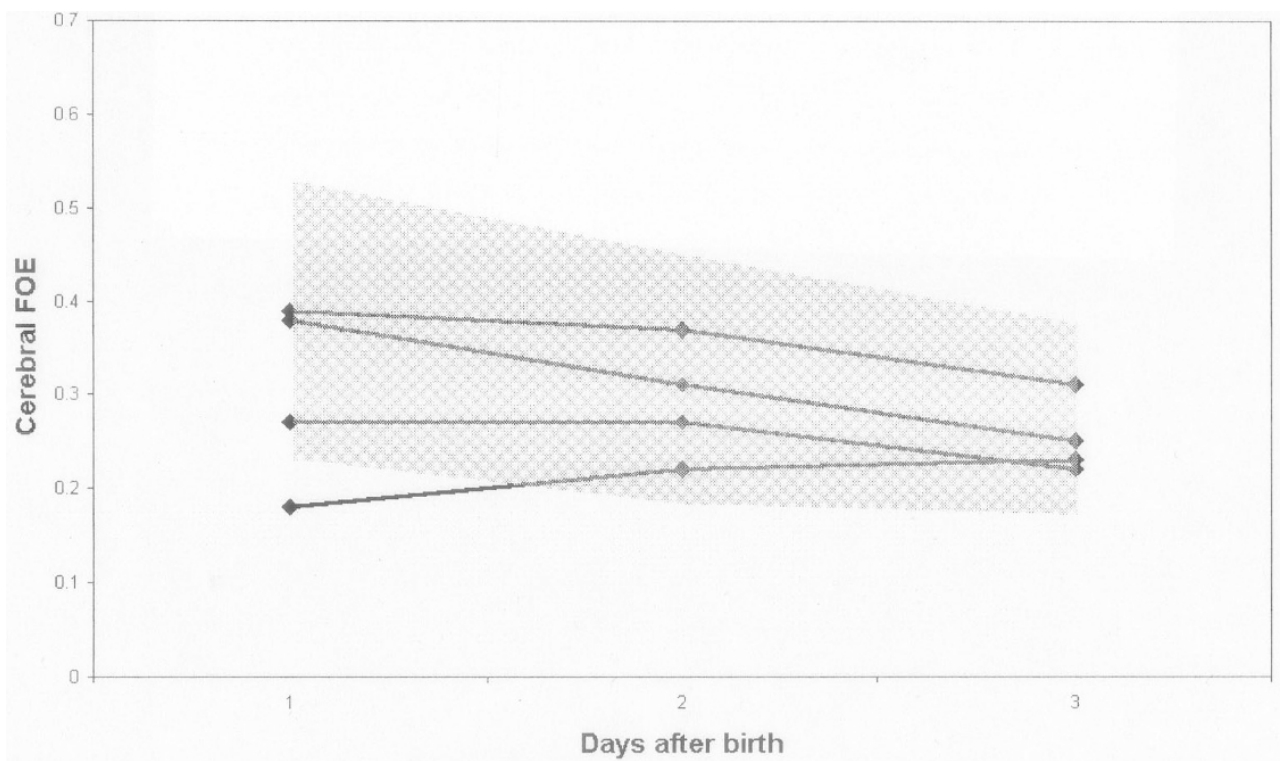

Figure 3. Cerebral FOE during the first $3 \mathrm{~d}$ after birth in four infants with cystic PVL. Data for individual infants are plotted separately, against the shaded area, which represents the range covered by the $5^{\text {th }}$ to $95^{\text {th }}$ centiles for cerebral FOE in infants with no major cerebral injury. Median cerebral FOE did not change significantly during the $3 \mathrm{~d}$. One measurement of cerebral FOE was below the $5^{\text {th }}$ to $95^{\text {th }}$ centile range.

bral ventricles, and two had accompanying HPI. The median (interquartile range) day of detection of IVH was $\mathrm{d} 3$ (d 1-5). In the two infants designated A and B who also developed HPI, the parenchymal lesions were first visualized on cranial ultrasound scan on $\mathrm{d} 3$ following the occurrence of IVH on $\mathrm{d} 1$.

Cerebral FOE of the nine infants with IVH demonstrated significant differences over the $3 \mathrm{~d}$ of measurement (Table 2). From $\mathrm{d} 1$ to $\mathrm{d} 2$, median cerebral FOE decreased by $33.3 \%$ ( $p$ $=0.05)$, and from $\mathrm{d} 2$ to $\mathrm{d} 3$ there was an increase of $41.6 \%$ ( $p$ $=0.05$ ). Five of 21 measurements of cerebral FOE fell outside the normal limits generated from data in infants with no major cerebral injury (Fig. 4). All five had cerebral FOE above the $95^{\text {th }}$ centile.

The two infants with IVH and HPI accounted for two of the five high recordings of cerebral FOE, as illustrated in Figure 4. These were the two highest values of cerebral FOE recorded during the study.

\section{DISCUSSION}

This study has demonstrated a striking difference in cerebral FOE during the first $3 \mathrm{~d}$ after birth when comparing infants who developed cerebral hemorrhage and those with no major

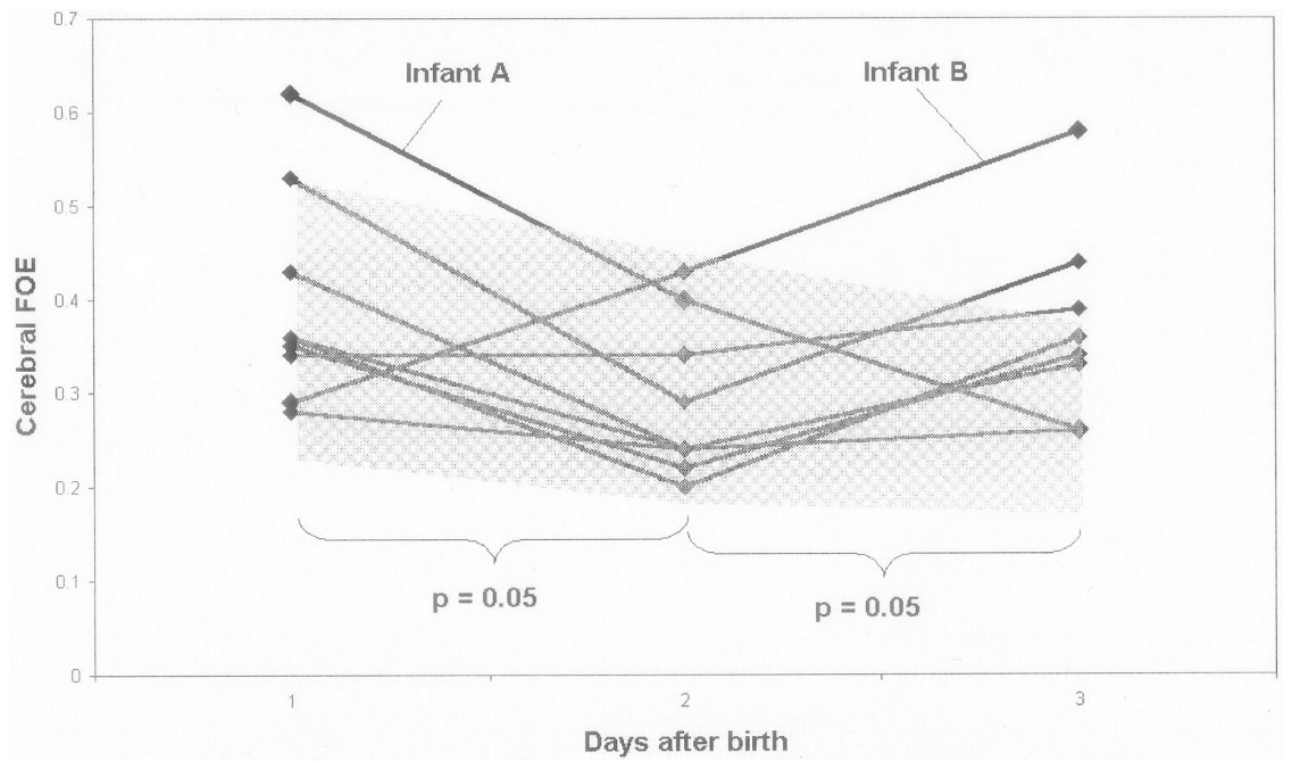

Figure 4. Cerebral FOE during the first $3 \mathrm{~d}$ after birth in nine infants with IVH, including two with HPI. Data for individual infants are plotted separately, against the shaded area, which represents the $5^{\text {th }}$ to $95^{\text {th }}$ centile range for cerebral FOE in infants with no major cerebral injury. Median cerebral FOE decreased significantly from $\mathrm{d} 1$ to $\mathrm{d} 2$, and increased significantly from $\mathrm{d} 2$ to 3 . Five of 21 measurements were above the $5^{\text {th }}$ to $95^{\text {th }}$ centile range for cerebral FOE in infants with no major cerebral injury. Two infants $(A$ and $B)$ also had HPI. 
cerebral injury. Because cerebral FOE represents the ratio of oxygen consumption to oxygen delivery, very high values of cerebral FOE imply that cerebral oxygen delivery was low, most probably because of cerebral hypoperfusion. Thus, our findings lend support to the observations that IVH and HPI are postnatal events, as a consequence of altered cerebral hemodynamics and oxygen delivery following birth. By contrast, infants who developed cystic PVL had cerebral FOE measurements that were similar to those in infants with no major injury.

There was a significant decrease in cerebral FOE during the first $2 \mathrm{~d}$ after birth in our cohort of ventilated preterm infants, but no change between $\mathrm{d} 2$ and 3 . In infants with no cerebral injury, or small subependymal hemorrhages alone, there was no significant change at all during the $3 \mathrm{~d}$. The finding that cerebral FOE was higher on d 1 compared with $\mathrm{d} 2$ and 3 suggests that cerebral oxygen delivery, and therefore cerebral blood flow, was lower on $\mathrm{d} 1$ than on subsequent days. There are several possible explanations for this finding. Firstly, preterm infants may have depressed cardiac function, lower systemic output, and lower blood pressure on the first day after birth when compared with subsequent days (27). Secondly, cerebral blood flow may be reduced on $\mathrm{d} 1$ after resuscitation using high concentrations of oxygen, which has a vasoconstricting effect on the cerebral vasculature (28).

In the four infants with cystic PVL, three of whom developed cysts late in the neonatal period, the pattern of change of cerebral FOE was similar to that seen in infants with no injury or subependymal hemorrhage alone. There was no significant change in cerebral FOE during the $3 \mathrm{~d}$, with all data points (except for one, which was below the $5^{\text {th }}$ centile) lying between the $5^{\text {th }}$ and $95^{\text {th }}$ centiles for cerebral FOE in infants with no major cerebral injury. This relative lack of fluctuation in cerebral FOE implies stable cerebral perfusion. The absence of any values of cerebral FOE above the $95^{\text {th }}$ centile implies that none of the infants had cerebral hypoperfusion or hypoxia at the time of measurement. These findings suggest that over the first $3 \mathrm{~d}$ after birth, cerebral hypoperfusion, cerebral hypoxia, or fluctuations in cerebral blood flow are not associated with the development of cystic PVL.

By contrast with those infants with no serious cerebral injury and those who developed cystic PVL, the nine infants with IVH exhibited marked variation in cerebral FOE over the $3 \mathrm{~d}$ of measurement. Cerebral FOE decreased significantly from d 1 to 2 , and increased significantly from $\mathrm{d} 2$ to 3 . Five measurements of cerebral FOE in those infants with IVH and HPI were outside the $5^{\text {th }}-95^{\text {th }}$ centile limits for infants with no major cerebral injury, all of which were above the $95^{\text {th }}$ centile. It would seem, therefore, that the infants with cerebral hemorrhage had a more labile cerebral circulation than infants who suffered no major cerebral injury. These observations support the proposition made by other authors who have postulated that fluctuation in cerebral blood flow is an important etiological factor in the development of IVH and HPI $(9,29-32)$.

The nine infants with IVH included two with HPI, and these infants had very high and variable values of cerebral FOE during the $3 \mathrm{~d}$ of measurement. Infant A had very high cerebral FOE on $\mathrm{d} 1$, when the cranial ultrasound scan was normal, but this decreased to within the normal range on $\mathrm{d} 2$ and 3 , when
HPI was detected. Infant B had normal cranial ultrasound on d 2 , when cerebral FOE was very close to the $95^{\text {th }}$ centile. On $d$ 3 , cranial ultrasound demonstrated the presence of HPI, and cerebral FOE had increased to considerably above the $95^{\text {th }}$ centile.

The observation that severe hemorrhage occurred at around the time when cerebral FOE was extremely high supports a notion that disturbed cerebral hemodynamics may be involved in the pathogenesis of HPI. In our series, the two highest recorded values of cerebral FOE were in the only two infants with HPI. Increased cerebral FOE is likely to be a consequence of reduced cerebral oxygen delivery caused by reduced cerebral blood flow. This finding is in agreement with other studies, which have demonstrated that cerebral blood flow was significantly lower in infants who developed IVH than those who did not, and that those infants with the most severe lesions had the lowest cerebral blood flow $(33,34)$.

In conclusion, this study has demonstrated a significant decrease in cerebral FOE during the first $2 \mathrm{~d}$ after birth in a cohort of sick, ventilated, preterm infants. This is despite difficulties in obtaining data suitable for analysis using nearinfrared spectroscopy, an operator-dependent process that is very sensitive to movement artifact, which resulted in a number of infants being excluded from the analysis. This decrease in cerebral FOE implies an increase in cerebral oxygen delivery during this time. Cerebral FOE was stable in infants with no major cerebral injury and infants who develop cystic PVL, but fluctuated in those who developed IVH confined to the ventricles and HPI. As cerebral FOE reflects cerebral oxygen delivery and thus cerebral blood flow, these observations support the proposition that fluctuating hemodynamics may play an important role in the etiology of IVH and HPI, but that different factors, such as cytokines, are likely to be responsible for the development of cystic PVL.

\section{REFERENCES}

1. Hesser U, Katz-Salamon M, Mortensson W, Flodmark O, Forssberg H 1997 Diagnosis of intracranial lesions in very-low-birthweight infants by ultrasound: incidence and association with potential risk factors. Acta Paediatr Suppl 419:16-26

2. Cooke RW 1999 Trends in incidence of cranial ultrasound lesions and cerebral palsy in very low birthweight infants 1982-93. Arch Dis Child Fetal Neonatal Ed 80:F115F117

3. Gleissner M, Jorch G, Avenarius S 2000 Risk factors for intraventricular hemorrhage in a birth cohort of 3721 premature infants. J Perinat Med 28:104-110

4. Vohr BR, Wright LL, Dusick AM, Mele L, Verter J, Steichen JJ, Simon NP, Wilson DC, Broyles S, Bauer CR, Delaney-Black V, Yolton KA, Fleisher BE, Papile LA, Kaplan MD 2000 Neurodevelopmental and functional outcomes of extremely low birth weight infants in the National Institute of Child Health and Human Development Neonatal Research Network, 1993-1994. Pediatrics 105:1216-1226

5. Wood NS, Marlow N, Costeloe K, Gibson AT, Wilkinson AR 2000 Neurologic and developmental disability after extremely preterm birth. EPICure Study Group. N Engl J Med 343:378-384

6. Volpe JJ 1998 Brain injury in the premature infant: overview of clinical aspects, neuropathology, and pathogenesis. Semin Pediatr Neurol 5:135-151

7. Volpe JJ 2001 Neurology of the Newborn. WB Saunders, Philadelphia, pp 217-497

8. Calvert SA, Ohlsson A, Hosking MC, Erskine L, Fong K, Shennan AT 1988 Serial measurements of cerebral blood flow velocity in preterm infants during the first 72 hours of life. Acta Paediatr Scand 77:625-631

9. Perlman JM, Volpe JJ 1990 Fluctuating blood pressure and intraventricular hemorrhage. Pediatrics 85:620-622

10. Bada HS, Korones SB, Perry EH, Arheart KL, Ray JD, Pourcyrous M, Magill HL, Runyan III W, Somes GW, Clark FC 1990 Mean arterial blood pressure changes in premature infants and those at risk for intraventricular hemorrhage. J Pediatr 117:607-614

11. D'Souza SW, Janakova H, Minors D, Suri R, Waterhouse J, Appleton G, Ramesh C, Sims DG, Chiswick ML 1995 Blood pressure, heart rate, and skin temperature in 
preterm infants: associations with periventricular haemorrhage. Arch Dis Child Fetal Neonatal Ed 72:F162-F167

12. Wigglesworth JS, Pape KE 1980 Pathophysiology of intracranial haemorrhage in the newborn. J Perinat Med 8:119-133

13. Calvert SA, Hoskins EM, Fong KW, Forsyth SC 1987 Etiological factors associated with the development of periventricular leukomalacia. Acta Paediatr Scand 76:254-259

14. Blankenberg FG, Loh NN, Norbash AM, Craychee JA, Spielman DM, Person BL, Berg CA, Enzmann DR 1997 Impaired cerebrovascular autoregulation after hypoxicischemic injury in extremely low-birth-weight neonates: detection with power and pulsed wave Doppler US. Radiology 205:563-568

15. Watkins AM, West CR, Cooke RW 1989 Blood pressure and cerebral haemorrhage and ischaemia in very low birthweight infants. Early Hum Dev 19:103-110

16. Gronlund JU, Korvenranta H, Kero P, Jalonen J, Valimaki IA 1994 Elevated arteria blood pressure is associated with peri-intraventricular haemorrhage. Eur J Pediatr 153:836-841

17. Cunningham S, Symon AG, Elton RA, Zhu C, McIntosh N 1999 Intra-arterial blood pressure reference ranges, death and morbidity in very low birthweight infants during the first seven days of life. Early Hum Dev 56:151-165

18. Dammann O, Leviton A 1997 Maternal intrauterine infection, cytokines, and brain damage in the preterm newborn. Pediatr Res 42:1-8

19. Kinney HC, Back SA 1998 Human oligodendroglial development: relationship to periventricular leukomalacia. Semin Pediatr Neurol 5:180-189

20. Wu YW, Colford Jr JM 2000 Chorioamnionitis as a risk factor for cerebral palsy: a meta-analysis. JAMA 284:1417-1424

21. Younkin DP, Reivich M, Jaggi JL, Obrist WD, Delivoria-Papadopoulos M 1987 The effect of hematocrit and systolic blood pressure on cerebral blood flow in newborn infants. J Cereb Blood Flow Metab 7:295-299

22. Pryds O, Andersen GE, Friis-Hansen B 1990 Cerebral blood flow reactivity in spontaneously breathing, preterm infants shortly after birth. Acta Paediatr Scand 79:391-396

23. Tyszczuk L, Meek J, Elwell C, Wyatt JS 1998 Cerebral blood flow is independent of mean arterial blood pressure in preterm infants undergoing intensive care. Pediatrics $102: 337-341$
24. Pellicer A, Gaya F, Stiris TA, Quero J, Cabanas F 1998 Cerebral haemodynamics in preterm infants after exposure to dexamethasone. Arch Dis Child Fetal Neonatal Ed 79:F123-F128

25. Yoxall CW, Weindling AM, Dawani NH, Peart I 1995 Measurement of cerebral venous oxyhemoglobin saturation in children by near-infrared spectroscopy and partial jugular venous occlusion. Pediatr Res 38:319-323

26. Yoxall CW, Weindling AM 1998 Measurement of cerebral oxygen consumption in the human neonate using near infrared spectroscopy: cerebral oxygen consumption increases with advancing gestational age. Pediatr Res 44:283-290

27. Evans N, Kluckow M 1996 Early determinants of right and left ventricular output in ventilated preterm infants. Arch Dis Child Fetal Neonatal Ed 74:F88-F94

28. Lundstrom KE, Pryds O, Greisen G 1995 Oxygen at birth and prolonged cerebral vasoconstriction in preterm infants. Arch Dis Child Fetal Neonatal Ed 73:F81F86

29. Fujimura M, Salisbury DM, Robinson RO, Howat P, Emerson PM, Keeling JW, Tizard JP 1979 Clinical events relating to intraventricular haemorrhage in the newborn. Arch Dis Child 54:409-414

30. Perlman JM, McMenamin JB, Volpe JJ 1983 Fluctuating cerebral blood-flow velocity in respiratory-distress syndrome. Relation to the development of intraventricular hemorrhage. N Engl J Med 309:204-209

31. Perlman JM, Goodman S, Kreusser KL, Volpe JJ 1985 Reduction in intraventricular hemorrhage by elimination of fluctuating cerebral blood-flow velocity in preterm infants with respiratory distress syndrome. N Engl J Med 312:1353-1357

32. Kempley ST, Vyas S, Bower S, Nicolaides KH, Gamsu H 1996 Cerebral and renal artery blood flow velocity before and after birth. Early Hum Dev 46:165174

33. Ment LR, Duncan CC, Ehrenkranz RA, Lange RC, Taylor KJ, Kleinman CS, Scott DT, Sivo J, Gettner P 1984 Intraventricular hemorrhage in the preterm neonate: timing and cerebral blood flow changes. J Pediatr 104:419-425

34. Meek JH, Tyszczuk L, Elwell CE, Wyatt JS 1999 Low cerebral blood flow is a risk factor for severe intraventricular haemorrhage. Arch Dis Child Fetal Neonatal Ed 81:F15-F18 